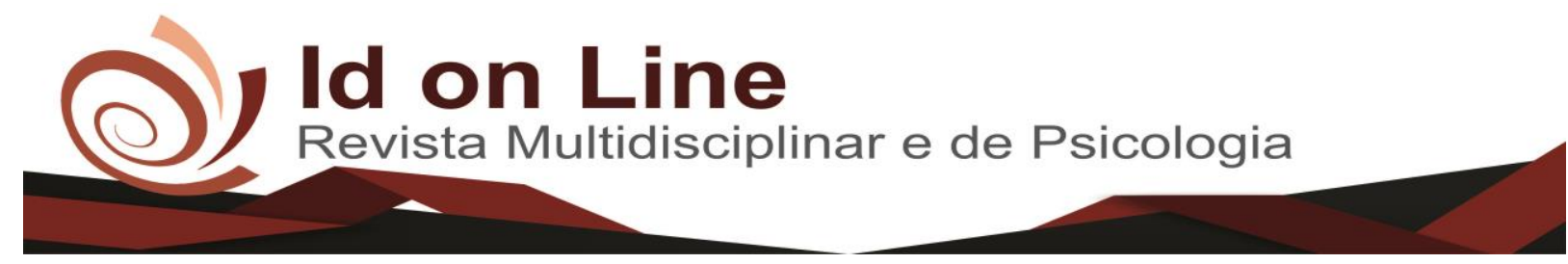

Artigo de Revisão

\title{
Liderança e Clima Organizacional: apontamentos a partir de uma pesquisa bibliográfica.
}

Renato Santiago Quintal ${ }^{\text {; }}$ Robson Augusto Dainez Condé2

\begin{abstract}
Resumo: O artigo em tela apresenta como tema as contribuições da liderança ao estabelecimento de um clima organizacional profícuo. Justifica-se realizar o presente artigo pela relevância e atualidade do tema, notadamente pelo fato de ser objeto de estudo dos mais distintos grupos, nos mais diversos fóruns. Nesse contexto, o objetivo deste estudo é produzir uma breve análise sobre a temática afeta à liderança e suas contribuições ao estabelecimento de um clima organizacional frutífero. Conforme a natureza dos dados, a pesquisa em comento pode ser classificada como qualitativa e bibliográfica. Buscou-se responder a seguinte questão de pesquisa: Em que medida as informações levantadas ao longo da presente pesquisa poderão confirmar ou não as contribuições da liderança ao estabelecimento de um clima organizacional exitoso? Verifica-se que a liderança exerce um papel significativo na harmonização do clima organizacional, especialmente por viabilizar atributos como: confiança; harmonia e coerência; comunicação fluida; qualidade de vida laboral; diversidade; criatividade; inovação; e produtividade.
\end{abstract}

Palavras-chave: Liderança. Comportamento Organizacional. Psicologia militar.

\section{Leadership and Organizational Climate: notes from a bibliographical research}

\begin{abstract}
The article on the topic presents the contributions of leadership to the establishment of a productive organizational climate. It is justified to carry out the present article because of the relevance and timeliness of the theme, especially because it is the object of study of the most distinct groups in various forums. In this context, the objective of this study is to produce a brief analysis on the issue affecting leadership and its contributions to the establishment of a fruitful organizational climate. According to the nature of the data, the research in comment can be classified as qualitative and bibliographical. It was sought to answer the following research question: To what extent the information gathered throughout the present research can confirm or not the contributions of the leadership to the establishment of a successful organizational climate? It is verified that leadership plays a significant role in the harmonization of the organizational climate, especially for enabling attributes such as: trust; harmony and coherence; fluid communication; quality of working life; diversity; creativity; innovation; and productivity.
\end{abstract}

Keywords: Leadership. Organizational behavior. Military psychology.

\footnotetext{
${ }^{1}$ Mestre em Ciências Contábeis (Faculdade de Administração e Finanças da Universidade do Estado do Rio de Janeiro/FAF-UERJ); Especialista em Educação Tecnológica (Centro Federal de Educação Tecnológica Celso Suckow da Fonseca/CEFET-RJ); Especialista em Comércio Exterior (Instituto de Economia da Universidade Federal do Rio de Janeiro/IE-UFRJ); Especialista em Gerenciamento de Projetos (Fundação Getúlio Vargas/FGV); Bacharel em Direito (Faculdade Nacional de Direito/UFRJ); Bacharel em Ciências Navais (Escola Naval/EN); Licenciado em Pedagogia (UNIRIO); e Bacharel em Administração (Universidade Cândido Mendes/UCAM). Membro do Corpo Editorial da Revista PAGMAR (ISSN 2318-1702 versão impressa e ISSN 2446-4791 versão online). E-mail: rsantiago79@ hotmail.com;

${ }^{2}$ Mestre em Ciências Contábeis (UERJ - 2013). Bacharel em Direito (Faculdade de Direito de Vila Velha - 2008). Bacharel em Ciências Navais (Escola Naval - 1995). Especialização em Administração (CIAW-1996). Aperfeiçoamento_ Gestão Pública (CIAW-1998). Auditor Fiscal da Receita do Estado do Espírito Santo. Professor de Pós-Graduação da Faculdade Castelo Branco. Membro do Corpo Editorial da Revista PAGMAR (ISSN 2318-1702 e ISSN 2446-4791 online). E-mail: robsonconde@ hotmail.com.
} 


\section{Introdução}

$\mathrm{O}$ artigo em tela apresenta como tema as contribuições da liderança ao estabelecimento de um clima organizacional profícuo nas organizações. Justifica-se realizar a presente monografia pela relevância e atualidade do tema, notadamente pelo fato de ser objeto de estudo dos mais distintos grupos, em diversos fóruns, dentre os quais se destacam: militares; empresariado; gestores públicos; e acadêmicos.

Nesse sentido, o objetivo do estudo é produzir uma breve análise sobre a temática afeta à liderança e suas contribuições ao estabelecimento de um clima organizacional frutífero. Sob esse prisma, a questão de pesquisa formulada foi a seguinte: Em que medida as informações levantadas ao longo da presente pesquisa poderão confirmar ou não os reflexos da liderança no estabelecimento de um clima organizacional exitoso?

\section{Método}

Conforme a natureza dos dados, a presente pesquisa pode ser classificada como qualitativa e bibliográfica (GIL, 2010).

No que tange ao detalhamento das publicações que suportaram teoricamente a presente pesquisa, foram selecionados os livros disponíveis no acervo de aproximadamente 32.000 mil títulos da biblioteca da Escola de Guerra Naval (EGN), uma instituição de altos estudos militares pertencente à Marinha do Brasil, no período compreendido entre 2013 e 1982.

Optou-se por aquelas publicações que tratavam dos temas a seguir, os quais foram empregados como palavras-chave para se empreender a pesquisa ao título e à sinopse daquele acervo: clima organizacional; psicologia militar; liderança; liderança militar; liderança naval; e relacionamento superior-subordinado. Adicionalmente, foi empreendida a leitura da sinopse de 80 livros e selecionado o quantitativo de 11 obras, cujo conteúdo se encontrava aderente à proposta do presente trabalho. O quadro 1 abaixo apresenta as obras selecionadas para fins desta pesquisa e as suas principais características. 


\begin{tabular}{|c|c|c|c|}
\hline Temáticas abordadas & Título da obra & Autor & Ano \\
\hline $\begin{array}{c}\text { Clima organizacional; Psicologia } \\
\text { militar; Liderança; Liderança militar; } \\
\text { Liderança naval; Relacionamento } \\
\text { superior-subordinado }\end{array}$ & $\begin{array}{c}\text { Este barco é nosso: dicas práticas } \\
\text { sobre liderança e cooperação do } \\
\text { comandante do melhor navio de } \\
\text { guerra da marinha americana }\end{array}$ & Michael Abrashoff & 2013 \\
\hline $\begin{array}{c}\text { Clima organizacional; Psicologia } \\
\text { militar; Liderança; Liderança militar; } \\
\text { Relacionamento superior-subordinado }\end{array}$ & O Líder sem Estado-Maior & Carlos Matus & 2000 \\
\hline $\begin{array}{c}\text { Clima organizacional; Psicologia } \\
\text { militar; Liderança; Liderança militar; } \\
\text { Relacionamento superior-subordinado. }\end{array}$ & A máscara do comando & John Keegan & 1999 \\
\hline $\begin{array}{c}\text { Clima organizacional; Psicologia } \\
\text { militar; Liderança; Liderança militar; } \\
\text { Relacionamento superior-subordinado }\end{array}$ & Liderança militar & Jarbas Passarinho & 1987 \\
\hline $\begin{array}{c}\text { Clima organizacional; Liderança; } \\
\text { Relacionamento superior-subordinado. }\end{array}$ & Técnica de Chefia e liderança & $\begin{array}{c}\text { José Roberto } \\
\text { Whitaker Penteado }\end{array}$ & 1986 \\
\hline $\begin{array}{c}\text { Clima organizacional; Liderança; } \\
\text { Relacionamento superior-subordinado. }\end{array}$ & Chefia e liderança & Albino Nogueira de \\
\hline Faria & 1982 \\
\hline Clima organizacional; Liderança & $\begin{array}{c}\text { Liderança e sustentabilidade: } \\
\text { dilemas, desafios e propósitos - } \\
\text { guia prático e conceitual }\end{array}$ & $\begin{array}{c}\text { Maiza Neville; } \\
\text { Regina Drumond }\end{array}$ & 2010 \\
\hline Clima organizacional; Liderança & Liderança no limite & Dennis Perkins & 2002 \\
\hline Clima organizacional; Liderança & Princípios absolutos de Liderança & Philip Crosby & 1999 \\
\hline Clima organizacional; Liderança & $\begin{array}{c}\text { A confiança inteligente: criando } \\
\text { prosperidade, energia e alegria } \\
\text { num mundo carente de confiança }\end{array}$ & $\begin{array}{l}\text { Stephen Covey; Greg } \\
\text { Link; Rebecca Merril }\end{array}$ & 2013 \\
\hline Clima organizacional; Liderança & O monge e o executivo & James Hunter & 2004 \\
\hline
\end{tabular}

Quadro 1: Obras selecionadas para fins desta pesquisa e as suas principais características

Fonte: Elaborado pelos autores

Posteriormente, foi empreendida uma leitura sistemática do material, viabilizando a realização de fichamento daquele conteúdo, o qual instruiu a elaboração da parte conceitual do presente artigo.

\section{Fundamentação Teórica}

\section{Liderança}

Penteado (1986) apresenta que liderança não representa outra coisa senão a função que o líder exerce. Trata-se de uma forma de dominação, associada ao exercício do poder. Nesse 
contexto, o autor em pauta revela que um aspecto que torna a conceituação de liderança dificultosa é o fato de a liderança representar um fenômeno social. Portanto, a liderança seria a função do líder que a empreende no e sobre um grupo, em um determinado contexto.

Hunter (2004) comenta que toda vez que dois ou mais indivíduos se reúnem com um objetivo, existe uma ocasião favorável ao exercício da liderança. O aludido autor aponta que a genuína liderança está ao alcance de todos, mas demanda uma significativa entrega pessoal e que o verdadeiro líder gerencia objetos e lidera pessoas. Nesse contexto, o autor em tela revela que a capacidade de influenciar pessoas, intrinsecamente associada à liderança, pode ser assimilada e fortalecida por aquele indivíduo que anseie e empreenda as ações convenientes. Hunter (2004) revela que somente quando houver a aderência das ações às intenções é que a liderança poderá ser exercida coerente e harmoniosamente.

Matus (2000) aponta que a definição de liderança confere relevância à aptidão que alguns indivíduos são detentores no que diz respeito à comoção, inspiração, mobilização e condução das massas, de maneira que entre as massas e o líder engendra-se uma aliança emocional e racional que os impele a marchar conjuntamente para o sucesso ou para a derrocada.

\section{O Líder}

Hunter (2004), em sua obra "O monge e o Executivo" consigna que ouvir é um dos principais atributos que o líder pode eleger como passível de desenvolvimento. Hunter (2004) aponta que os líderes genuinamente grandes detém a capacidade de conceber relacionamentos saudáveis, uma vez que os relacionamentos são relevantes quando se lidera. Nesse sentido, o amálgama que une os relacionamentos é a confiança.

Penteado (1986) revela que a caracterização do líder representa uma segunda tentativa do que a Psicologia vem empreendendo no que se refere à personalidade, delimitando os atributos individuais em um esforço de delinear uma personalidade padrão. Nesse sentido, para o autor em pauta, a caracterização do líder é capaz de viabilizar a tarefa daqueles indivíduos que buscam o seu aperfeiçoamento, explorando traços basilares positivos da intrincada personalidade humana. 
Nogueira de Faria (1982) apresenta que líder é aquele indivíduo que é seguido ainda que não disponha de nenhuma chefia ou autoridade previstas no estatuto da organização, pois tem a capacidade de ser aceito e respeitado, em função da capacidade de agregar as pessoas, representá-las e levá-las de forma coesa à busca e à defesa dos anseios comuns, de viabilizar um bom relacionamento e, adicionalmente, detém significativa identificação com os demais membros do grupo.

Para Matus (2000), a tarefa de delinear a personalidade de líderes não pode fugir da caricatura. Sabendo-se do risco de caricaturização, foi empregada pelo autor em tela a tipologia pura transcrita a seguir, a qual admite um nível substancial de combinações e dosagens, conforme a personalidade real de cada líder. Nesse sentido, tem-se: o líder transformador agressivo (dominante, pouco comum, impaciente e incansável); líder ordenador autoritário (imposição de ordem a qualquer preço, capacidade de tomar decisões críticas); líder transformador democrático (equilíbrio, capacidade de sacrifício, político); líder administrador (pragmático, gradualista e desconfiado); e cacique sem projeto social (competente dentro das suas possibilidades, astuto e detentor habilidades micropolíticas).

Hunter (2004) registra a necessidade de os líderes identificarem e atenderem as necessidades - e não as vontades - dos seus colaboradores, uma vez que as necessidades correspondem a legítimas demandas físicas ou psicológicas orientadas ao bem-estar humano, ao passo que as vontades são simples anseios que desconsideram os reflexos físicos ou psicológico do objeto de desejo.

Em um contexto do estudo das motivações, Nogueira de Faria (1982) aponta que o processamento normal inicia-se com a percepção, que estimula a imaginação, faz brotar evocações na memória, fomenta a comparação e o emprego da inteligência, podendo sentir os reflexos da compulsão da emotividade e alcançar a definição de alguma necessidade, como sendo algo capaz de promover a satisfação de um desejo.

Hunter (2004) registra que o recebimento de elogio é uma autêntica necessidade humana, fazendo-se presente nos relacionamentos saudáveis. Contudo, o aludido autor chama a atenção para a necessidade de esses elogios serem sinceros e específicos. Para ele, convém reforçar um comportamento específico, uma vez que aquilo que é reforçado volta a ser realizado. O autor em lide acrescenta que os elogios devem ser púbicos, ao contrário das punições, as quais devem ser ocorrer de forma reservada. Hunter (2004) chama a atenção para 
o fato de que o líder deve assumir um interesse especial pelo êxito dos seus liderados, apoiandoos e fomentando lhes o sucesso.

Penteado (1986) aponta que a capacidade do líder de motivar os subordinados é dependente da amplitude em que controla os meios que satisfazem as necessidades dos aludidos subordinados. Contudo, segundo o autor, um dos problemas contemporâneos vislumbrados é descobrir uma motivação que conduza os homens ao trabalho, uma vez que não se trata de uma fácil tarefa em uma sociedade marcada pela produção em série, onde muitos indivíduos não auferem de seus trabalhos mais que uma satisfação de cunho pessoal muito relativa, ou mesmo quase nenhuma realização.

Para Hunter (2004), a motivação está associada a qualquer tipo de comunicação que exerce influência em escolhas. Para o autor, o líder viabiliza as condições necessárias, mas as escolhas são feitas pelos indivíduos.

\section{Chefe, Grupo e Turma: afastando-se do senso comum}

Nogueira de Faria (1982) aponta que, majoritariamente, os chefes não detêm capacidade de liderança e que diversos líderes não estão investidos em cargos de direção ou chefia, uma vez que há distintos fatores que condicionam a investidura em cargos de natureza administrativa, tais como parentesco, habilidade política, confiança, amizade e antiguidade.

Segundo Nogueira de Faria (1982), chefe é aquele indivíduo detentor de autoridade formal adquirida via investidura, em um cargo contemplado na estrutura orgânica concebida, baseando-se no estatuto da instituição e cujas atribuições conferem àquele indivíduo capacidade para representá-lo, decidir e deliberar dentro das restrições de sua competência.

Nogueira de Faria (1982) assevera que, em termos práticos, o vocábulo chefe é empregado para identificar aquele indivíduo que detém o mando, investido ou não de autoridade formal, mas possuidor de alguma forma de poder. Majoritariamente, as pessoas não distinguem direção de chefia, quando, na verdade, há uma singela distinção. Diretor é aquele indivíduo que detém autoridade deliberativa, maneja os sistemas, funcionaliza a engrenagem administrativa ou operacional; alavanca os subordinados, os quais devem ser motivados, direcionados e 
liderados, com o fito de executarem suas tarefas com eficácia sem provocar problemas de relacionamento, viabilizando o trabalho em equipe.

Para Nogueira de Faria (1982), chefiar é converter em ação as ideias aprovadas por meio de deliberações e decisões; trata-se de impulsionar, orientar e liderar indivíduos incumbidos de tarefas necessárias ao alcance dos objetivos da organização, integrando essas tarefas em equipes de trabalho, pelo engendramento de grupos homogêneos, comprometidos com traçados estabelecidos.

Nogueira de Faria (1982) defende que grupo é uma reunião de pessoas em torno de um objetivo comum salvaguardado por um líder, cujas orientações devem ser acatadas por todos. Demanda de seus integrantes lealdade ao propósito que viabiliza a união, disposição para esforçar-se por ele, agindo e reagindo sob a forma de pressão perante aqueles que obstam a efetivação daqueles anseios.

A expressão Turma, para Nogueira de Faria (1982), é uma coletânea de pessoas agregadas para execução de certa tarefa, de modo formal a partir de um recrutamento empreendido por um chefe, e de modo informal, quando uma motivação bem traçada reúne indivíduos sem qualquer vínculo em determinado espaço. Para o autor, a turma pode ser convertida em grupo desde que passe a ser estimulada em prol de um objetivo perene e acate a orientação de um líder apto a gerar uma estrutura de relacionamento que ordene a ação. Nesse sentido, as turmas se constituem autênticas escolas de líderes e atuam como instrumentos reveladores de vocações.

Nogueira de Faria (1982) argumenta que a multidão está associada a uma reunião fortuita de muitos indivíduos pelas mais distintas razões. Nesse sentido, para o autor, os líderes preferem encontrar turmas e multidões que anseiam algum objetivo, uma vez que podem, de forma hábil, chamar para si a liderança, por intermédio de uma demonstração de ajustamento de cunho emocional e de lealdade ao objetivo preponderante. Segundo o autor em pauta, convém apontar que os chefes que não são líderes tem receio dos grupos e buscam desagregálos, por meio de dos mais distintos expedientes, ainda que seja atrapalhando de forma proposital o trabalho para fragmentar a sua estrutura e evitar a possível pressão proveniente de uma força com a qual não sabem lidar.

Nogueira de Faria (1982) argumenta que, majoritariamente, os indivíduos almejam e necessitam ser conduzidos, ainda quando revelam apreciar a liberdade e aparentam deter autossuficiência, uma vez que mesmo as detentoras de maior instrução e cultura raramente são 
capazes de deliberar e decidir, pois não reúnem os conhecimentos necessários nas searas de organização e administração, menos ainda as ferramentas e as metodologias do processo decisório.

Nogueira de Faria (1982) revela que, na condição de representante do grupo, o líder deve buscar de todos os modos cuidar da defesa dos companheiros e conduzi-los à realização dos propósitos estabelecidos de forma majoritária como sendo os principais. Adicionalmente, segundo o autor, faz-se necessário que o líder desenvolva o espírito de união a fim de possibilitar o emprego de uma força compulsiva suficientemente robusta a fim de fazer com que as autoridades e adversários tenham respeito pela sua ação, cedendo frente às pressões do grupo.

Para Nogueira de Faria (1982), o estudo das técnicas relacionadas a chefia e liderança tem o objetivo de viabilizar o bom desempenho no emprego da autoridade e no relacionamento, por intermédio da disponibilidade de conhecimentos afetos ao manejo e à dinâmica de grupo. Nesse sentido, determinados indivíduos podem já nascerem detentores das habilidades de chefia e liderança; contudo, unicamente essa potencialidade não basta. O sucesso no desempenho é diretamente proporcional dos esforços empreendidos em estudo e treinamento.

\section{Análise e Discussão}

\section{Liderança no contexto militar}

Passarinho (1987) aponta que a Primeira Guerra Mundial é a referência de nova fase nas relações estabelecidas entre comandantes e comandados. Naquele período, a psiquiatria começa a se afirmar entre as ciências. $\mathrm{O}$ autor em tela argumenta que, ao tornarem públicas as neuroses, os médicos reabilitaram combatentes responsabilizados por aparente covardia diante do antagonista. Nesse contexto, aqueles profissionais da saúde invalidam a prerrogativa dos chefes realizarem julgamentos acerca do comportamento dos homens pela aparência. Para o autor em tela, fazia-se necessário estudar a estrutura da personalidade humana.

Matus (2000) apresenta que a condição propícia ao exercício da liderança surge justamente porque a cegueira institucional do líder é inferior a do indivíduo comum. Além 
disso, Matus (2000) apresenta que o líder pavimenta caminhos onde a história e as circunstâncias o possibilitam. Nesse sentido, a Segunda Guerra Mundial não foi uma concepção de Churchill, porém algo imposto pela história e, a partir dessa imposição, criou condições propícias para a derrota alemã.

Passarinho (1987) revela que, ao longo do tempo, as relações de trabalho sofreram evoluções. Do regime escravocrata à sindicalização contemporânea, um longo trajeto foi seguido. Nos dias atuais, segundo o autor em comento, estuda-se a psicologia das relações humanas no ambiente de trabalho, a fim de se compreender como um chefe deve atuar, quais são os atributos da boa e da má liderança, como reconhecer as categorias de personalidade, com o objetivo de alcançar o máximo de cooperação por parte dos colaboradores.

Passarinho (1987) registra que a psicotécnica proporcionou uma valiosa colaboração, no sentido de possibilitar a maximização do rendimento do trabalho pela utilização do homem na atividade que lhe seja mais oportuna, adequada as suas aptidões e vocações. Passarinho (1987) adverte para o fato de que não se pode correr o risco advindo da improvisação de chefes, muito menos permitir que o recurso de direção de homens seja desenvolvido, aos poucos, à custa da nefasta experiência de equívocos acumulados. Passarinho (1987) recorda passagem do livro de memórias do General Patton, herói de guerra norte-americano, em que aquele General revela que o medo é próprio do homem e que todo ser humano tem medo; quanto mais inteligente, mais medo tem o indivíduo. A bravura, para Patton, citado por Passarinho, consiste em suplantar o medo e jamais em não tê-lo. É nesse contexto que o chefe deve reconhecer a possibilidade de um subordinado, em um momento inicial, sentir medo, insegurança, e, no instante seguinte, esforços devem ser envidados para dominar esse tipo de sentimento.

Existem três maneiras distintas de direcionar a conduta humana, são elas: persuasão (chamamento à razão); coerção (chamamento ao dever); e sugestão (chamamento ao sentimento) (MIRA Y LOPEZ, 1949 apud PASSARINHO, 1987). Passarinho (1987) aponta que não existe a necessidade de que o líder seja um psicólogo e, tampouco, um psiquiatra, bastando que conheça bem os seus liderados. Adicionalmente, o arcabouço instrumental mínimo necessário para que o líder possa cumprir a sua missão está associado às noções práticas de Psicologia Militar. Passarinho (1987) revela que se trata de um artefato que possibilitará ao líder ocupar-se de diferentes tipos estruturais de personalidade, empregando o tratamento disciplinar adequado para cada uma delas. Passarinho (1987) apresenta que os elementos constitutivos da personalidade são: instinto (segurança, gregário, poder e sexual); consciência 
(discernimento entre certo/ errado e bem/mal); e ego (associado à busca pela consideração desenvolvida em sociedade). Para Passarinho (1987), não existem homens iguais, o que representa afirmar que na seara da psicologia os tipos de personalidade divergem de um indivíduo para outro, não havendo como reduzi-los a um único tipo. Nesse diapasão, o fato de obter êxito ao se lidar com um determinado tipo de personalidade, não assegura que a mesma metodologia será igualmente boa para os demais tipos psicológicos.

Ainda no contexto militar, Keegan (1999) aponta que o generalato representa muito mais do que o comando de exércitos em campanhas militares. Para o autor, o exército representa a expressão da sociedade de onde ele é proveniente. Os objetivos pelos quais ele combate e a maneira como o faz são estabelecidos, majoritariamente, por aquilo que uma sociedade almeja de uma guerra e até que ponto ela espera que o seu exército atinja esse resultado. Desde que seja detentor de uma personalidade invulgar e um modo de se comportar eficaz, um general pode ser responsável tanto pela condução da sociedade como do exército para muito além de onde se esperava atingir.

\section{Reflexos no Clima organizacional}

Hunter (2004) aponta que os empregados gastam pelo menos doze horas do dia labutando e convivendo no ambiente de trabalho gerido pelos líderes, muitas vezes de forma displicente, sem mensurar o impacto produzido na vida dos seus liderados.

Abrashoff (2013) aponta que tanto na Marinha quanto no âmbito empresarial, faz-se necessário muito mais do que uma singela ordem para conservar a equipe operando em harmonia. Para o autor, o clima organizacional precisa fomentar a confiança mútua entre os indivíduos; a geração de um clima de confiança inicia-se com o Comandante. Para Abrashoff (2013), se os seus liderados identificarem sinais de comportamento egoísta, contraditório, hipócrita ou evasivo, automaticamente serão tomados por um sentimento de desconfiança, que pode provocar a ruína de organizações militares e carreiras, de modo que é necessário aprimorar o sentimento de confiança a todo custo.

Segundo Crosby (1999), ao engendrar um clima de consideração no qual os indivíduos são chamados a fazerem o melhor que podem, as organizações devem se perguntar o que 
gostaria de ter em termos de clima organizacional. Nesse sentido, para o autor, toda organização necessita ser vislumbrada como uma folha de papel a ser preenchida. Se cada sistema e cargo da organização tiver uma vida independente, os privilégios poderão congestionar a organização e a tradição igualmente poderá bloqueá-la. Crosby (1999) aponta que a organização aumentará em quantitativo de pessoas, contudo não em termos de eficiência; quando o controle da organização se torna extremamente difícil, a redução não planejada dos quadros de pessoal é inevitável.

Covey et al (2013) apontam que as capas dos jornais e os levantamentos estatísticos comprovam que o mundo encontra-se mergulhado em uma crise de confiança, a qual tem impactado profundamente o bem-estar econômico e a qualidade de vida das pessoas. Para os autores, quando a confiança aumenta em um relacionamento, em uma equipe, em uma empresa ou em um país, os indivíduos são capazes de se comunicar de forma mais rápida, de cooperarem melhor, de inovar mais e empreender negócios de forma mais rápida e eficiente.

Covey et al (2013) registram que, majoritariamente, as pessoas, tanto em cargos de chefia como operacionais, almejam ser dignas de confiança e trabalhar em espaços de elevada confiança. Os autores revelam que, em um ambiente em que as pessoas não são merecedoras de confiança, desmotivam-se ou pedem demissão, especialmente os profissionais de alta performance. Nesse sentido, apontam que a rotatividade de pessoal em um ambiente de reduzida confiança é significativamente maior que numa cultura de elevada confiança.

Covey et al (2013) exortam ao estabelecimento de laços de confiança e à assunção daqueles compromissos os quais tem a perspectiva de serem cumpridos. Caso não seja possível o cumprimento desses compromissos, faz-se necessária à imediata e clara comunicação da impossibilidade do cumprimento, bem como a reprogramação ou a renegociação de soluções alternativas. São ações que conservam a confiança da chefia, do círculo de amigos, de um componente da equipe, de um cliente, de um colaborador, de um parceiro, de um familiar ou de um amigo.

Neville e Drumond (2010) argumentam que se vive na atualidade a crise da sustentabilidade e do desenvolvimento, estando a pauta das discussões voltadas para como satisfazer as demandas com o mínimo comprometimento das gerações vindouras. Nesse contexto, na seara da criatividade e da inovação, faz-se necessário um novo ponto de vista para se observar a liderança e a gestão. Para as autoras, esse ponto de vista possibilita vislumbrar a 
liderança e as habilidades sociais sob o prisma do lugar em que atuam; portanto, inovar é transformar o comportamento de agentes, produtores e consumidores no mercado.

Neville e Drumond (2010) revelam que, em um contexto permanentemente competitivo, o desafio de distintas organizações é possuir em suas fileiras equipes e líderes inovadores e criativos, aptos a achar respostas para os desafios organizacionais, almejando metas em produtividade, rentabilidade e qualidade, assumindo como princípios norteadores valores socioambientais e éticos, com vistas especialmente à sustentabilidade nos negócios. Para as autoras, a intenção de se empreender inovações e transformações nos negócios necessita estar patente na organização, a qual deve estar motivada a fomentar e premiar esse tipo de comportamento, uma vez que lidar com indivíduos criativos e inovadores não é tão trivial quanto parece. Neville e Drumond (2010) indicam que o estabelecimento de um ambiente propício à produção criativa demanda que o líder disponibilize meios para que atitudes, valores e princípios partilhados por ele e seus colaboradores favoreçam o desenvolvimento de um processo de transformação mais robusto e sem percalços.

Para Crosby (1999), faz-se necessário que a organização deixe claro para os colaboradores que aqueles que produzem e crescem terão um tratamento adequado, a despeito de o emprego não ser garantido pelo resto da vida do colaborador. $\mathrm{O}$ autor em comento revela que a formulação de uma política do modo como os colaboradores serão tratados tem início com a determinação do propósito da organização, o qual deve estar voltado à auxiliar os indivíduos - colaboradores, cliente e fornecedores - a terem uma vida produtiva. Nesse sentido, para Crosby (1999), além de aspectos relacionados a programas de benefícios e compensação financeira, a organização viabiliza uma identidade que confere sentido à vida dos indivíduos. Dessa forma, Crosby (1999) aponta que quatro condições favorecem a criação de um clima gerador de produtividade, marcado pela criatividade e pela existência de um local agradável de trabalho, a saber: facilidade de acesso e comunicação com a direção/gerência; a conformação de um sistema de apoio realista, pautado em um programa de benefícios bem selecionado e gerido; sistema de avaliação justo; e um programa de remuneração adequado.

Para Neville e Drumond (2010), uma maneira de se lidar com a inovação em uma organização é estabelecer coletivos de empreendimentos internos. Esses grupos são constituídos por um indivíduo ou equipe responsável por avançar uma orientação até que um resultado seja alcançado. As autoras em pauta comentam que sua atribuição é produzir ideias nas quais os trabalhadores sejam capazes de labutar de forma conjunta a fim de desenvolverem 
produtos futuramente. $\mathrm{O}$ diferencial dos grupos reside no fato de que eles são os produtores das ideias e não os executores das ações idealizadas pelos líderes. Nesse sentido, melhores resultados são alcançados quando os grupos concebem as ideias do que quando o líder lhes força uma ideia a ser labutada. Desse modo, as autoras apontam que a melhor maneira de liderar indivíduos criativos é incentivá-los a expor as suas ideias abertamente, em um contexto que possibilite a inovação e a participação, em uma configuração que reúna os objetivos e valores da organização claramente estabelecidos. Portanto, para as autoras em lide, é fundamental que o líder estabeleça um clima organizacional que viabilize a fluidez de comportamentos e ideias a fim de que os colaboradores possam implementar soluções inovadoras e criativas.

Perkins (2002, p.181) revela que, caso um líder almeje trabalhar a sua aptidão para "liderar no limite" - em alusão a sua obra "Liderança no Limite" - faz-se necessário descobrir uma organização que fomente a boa liderança. Segundo o autor, para que indivíduo desfrute de todo o seu potencial como líder, deve atentar-se para a cultura da organização no qual está inserido.

Para Neville e Drumond (2010), a trajetória da inovação e da criatividade, atravessando barreiras organizacionais e individuais, é algo deveras subjetivo e fundamental. Um exame da forma como fomentar essa potencialidade humana pode ser de grande utilidade para lideranças baseadas em diversos grupos de interesse, socialmente responsáveis. Nesse sentido, para as autoras, é relevante estruturar equipes voltadas para a prática de produção de ideias, superação de desafios, aprendizagem acerca da diversidade, bem como para a busca de significado profissional e pessoal para os envolvidos. O fortalecimento e o aperfeiçoamento da performance funcional, ambiental e socioeconômica da organização viabilizam a sustentabilidade e a imagem da organização.

Para Neville e Drumond (2010), a essência legal e ética da atuação das organizações representa uma das basilares demandas do contexto econômico atual, o qual não atribui unicamente prioridade aos aspectos associados à produtividade e competitividade; outra questão importante para as organizações contemporâneas é a diversidade. Geralmente, segundo as autoras, as organizações representam o reflexo da realidade social do ambiente no qual estão inseridas, no qual ainda há a exclusão ou a preferência por relacionamentos caracterizados pela identificação com cada pessoa. Trata-se de um comportamento que produz reflexos diretos na constituição das equipes de trabalho, as quais se apresentam bastante homogêneas, menos aberta ao diálogo com distintas frações do mercado e pouco criativas. 
Para Neville e Drumond (2010), a conceituação de diversidade progressivamente vem sendo integrada às políticas internas das organizações, em um contexto de busca por ações afirmativas geradoras de condições que exibem um compromisso real com a ultrapassagem das desigualdades. As autoras em pauta apresentam que a diversidade no contexto interno da organização pode equivaler a uma substancial melhoria na qualidade de vida laboral. Segundo elas, no cenário extramuros da organização, no relacionamento com o mercado e com a sociedade, as iniciativas que privilegiam a diversidade podem representar uma substancial melhoria na imagem organizacional.

Para Neville e Drumond (2010), a comunicação, de forma reconhecida, se reveste de informações essenciais e necessita ser uma ferramenta perene de inteligência organizacional. Para as autoras, a comunicação agrega inúmeros saberes na articulação de relacionamentos, reputações e imagens; dessa forma, reveste-se de um cunho estratégico para as organizações. Segundo Neville e Drumond (2010), uma liderança focada em diversos grupos de interesse tem na comunicação organizacional o seu principal suporte para liderar processos de incorporação de valores, tratar questões de maior complexidade, de natureza ética, moral e socioambiental. Para assegurar um clima saudável na organização, segundo as autoras, o líder necessita sempre priorizar a divulgação das informações indispensáveis ao alinhamento da equipe com as situações e acontecimentos em que, direta ou indiretamente, estejam inseridos. Quando se deparam com a falta de comunicação ou de informações, Neville e Drumond (2010) destacam que os indivíduos são tomados por uma sensação de vulnerabilidade e insegurança, permitindo a propagação de boatos e medo, o que, usualmente, provoca uma crise de ansiedade que pode se desdobrar em uma crise real.

Para Neville e Drumond (2010), ainda que as coisas estejam a contento, o líder não deve cometer descuidos, pois o silêncio revela-se sempre como prejudicial. Trata-se de um indício de que existe uma concordância com tudo ou que os processos não estão sendo monitorados. Quando se está diante do público interno, segundo as autoras em pauta, faz-se necessário que o líder confira atenção diferenciada, notadamente em momentos de elevado estresse, ocasião em que as mensagens necessitam ser repetidas diversas vezes até que alcancem o patamar de maior compreensão e internalização integralmente pela equipe. Portanto, para as autoras em tela, a organização deve, de forma preferencial, considerar a comunicação direta com os liderados, assumindo como propósito a disseminação e o alinhamento das informações principais, especialmente as metas e os resultados. Esse paradigma de gestão de comunicação presencial 
possibilita que as equipes igualmente sejam escutadas. Contudo, como os instrumentos empregados na comunicação empresarial voltam-se para uma comunicação dirigida, Neville e Drumond (2010) denotam que o emprego da tecnologia da informação e comunicação atua como uma ferramenta de suporte à comunicação presencial, que é primeira forma de comunicação do líder.

\section{Conclusão}

Este artigo assumiu como tema as contribuições da liderança ao estabelecimento de um clima organizacional profícuo. Nesse sentido, o objetivo do estudo foi produzir uma breve análise sobre a temática afeta à liderança e suas contribuições ao estabelecimento de um clima organizacional frutífero.

Ao buscar a resposta para questão de pesquisa da presente monografia - Em que medida as informações levantadas ao longo da presente pesquisa poderão confirmar ou não as contribuições da liderança ao estabelecimento de um clima organizacional exitoso?-, verificase, à luz dos argumentos apresentados ao longo deste trabalho, que a liderança exerce um papel significativo na harmonização do clima organizacional, especialmente por viabilizar atributos como: confiança; harmonia e coerência; comunicação fluida; qualidade de vida laboral; diversidade; criatividade; inovação; e produtividade.

Por fim, a título de pesquisas futuras, sugere-se empreender um estudo de caso em escolas de formação da Marinha do Brasil a fim de constatar in loco os reflexos das práticas de liderança no estabelecimento de um clima organizacional que traga bons resultados para a organização.

\section{Referências}

ABRASHOFF, D. Michael. Este barco é nosso: dicas práticas sobre liderança e cooperação do comandante do melhor navio de guerra da marinha americana. Tradução Claudia Gerpe Duarte. São Paulo: Cultrix, 2013. 190p. 
COVEY, Stephen M. R.; LINK, Greg; MERRIL, Rebecca R. A confiança inteligente: criando prosperidade, energia e alegria num mundo carente de confiança. Tradução de Carlo s Szalak. Rio de Janeiro: Leya, 2013. 336p.

CROSBY, Philip. Princípios absolutos de Liderança. Tradução Roger David Frankel. São Paulo: Makron Books, 1999. 118p.

GIL, A. C. Como elaborar projetos de pesquisa. 5. ed. São Paulo: Atlas, 2010.

HUNTER, James. O monge e o executivo. Tradução de Maria da Conceição Fornos de Magalhães. Rio de Janeiro: Sextante, 2004. 139p.

KEEGAN, John. A máscara do comando. Tradução de Geraldo Pereira de Almeida Filho. Rio de Janeiro: Biblioteca do Exército, 1999. 399p.

MATUS, Carlos. O Líder sem Estado-Maior. Tradução de Giselda Barroso G. A. Sauveur. São Paulo: FUNDAP, 2000. 206p.

NEVILLE, Maiza; DRUMOND, Regina C. Liderança e sustentabilidade: dilemas, desafios e propósitos - guia prático e conceitual. Salvador: Casa da Qualidade, 2010. 210p.

NOGUEIRA DE FARIA, Albino. Chefia e Liderança. Rio de Janeiro: LTC - Livros Técnicos e Científicos, 1982. 214p.

PASSARINHO, Jarbas Gonçalves. Liderança Militar. Rio de Janeiro: Biblioteca do Exército, 1987. 166p.

PENTEADO, José Roberto Whitaker. Técnica de chefia e liderança. 7. ed. ver e atual. São Paulo: Pioneira, 1986. 186p.

PERKINS, N. T. Dennis. Liderança no Limite. Tradução Mônica Rosemberg. São Paulo: Makron Books, 2002. 230p.

\section{Como citar este artigo (Formato ABNT):}

QUINTAL, Renato Santiago e CONDÉ, Robson Augusto Dainez. Liderança e Clima Organizacional: apontamentos a partir de uma pesquisa bibliográfica. Id on Line Rev.Mult. Psic., 2018, vol.12, n.40, p.397-412. ISSN: 1981-1179.

Recebido: 04/04/2018

Aceito 12/04/2018 